\title{
Keterampilan Peribadi Pelajar Sebagai Satu Bentuk Kemahiran Komunikasi dan Kepentingannya dalam Pasaran Dunia Pekerjaan
}

\author{
NOOR AFZALIZA NAZIRA IBRAHIM \\ MAIZATUL HAIZAN MAHBOB \\ Universiti Kebangsaan Malaysia
}

\begin{abstract}
ABSTRAK
Artikel ini membincangkan keterampilan peribadi pelajar sebagai satu bentuk kemahiran komunikasi dan kepentingannya dalam pasaran dunia pekerjaan. Kemahiran komunikasi telah dikenal pasti sebagai satu elemen yang membantu graduan dalam mempertingkatkan kualiti keperibadian mereka. Manusia berkomunikasi kerana ingin mempengaruhi pemahaman orang lain, sikap dan juga tindakan pihak lain sama ada mereka bersetuju atau tidak ke atas sesuatu isu. Selain itu, komunikasi juga merupakan proses dua hala yang mana kedua-dua belah pihak harus memberi respons terhadap sesuatu maklumat yang disampaikan. Justeru kajian ini dijalankan dengan tujuan untuk menganalisis kemahiran komunikasi bukan lisan serta tahap keterampilan peribadi pelajar di UPM dan UMS. Data yang diperoleh menerusi kaedah survei dianalisis secara deskriptif dan inferensi dengan menggunakan analisis deskriptif min, korelasi dan regresi. Hasil dapatan menunjukkan kesedaran pelajar terhadap kemahiran komunikasi bukan lisan berada pada tahap tinggi. Begitu juga dengan keterampilan peribadi mereka, berada pada tahap tinggi. Sementara analisis regresi mendapati, kemahiran komunikasi bukan lisan memberi sumbangan varians ke atas keterampilan peribadi sebanyak 36.9 peratus. Dengan adanya keterampilan yang baik, pelajar dapat meningkatkan kemahiran diri masingmasing. Konsep keterampilan diri meliputi tiga elemen utama iaitu keterampilan komunikasi, kemahiran kepimpinan dan juga keterampilan bekerja dalam kumpulan. Graduan yang memiliki ketiga-tiga elemen ini akan memudahkan mereka membina keperibadian diri yang baik seterusnya membantu mereka membawa diri dalam dunia pekerjaan.
\end{abstract}

Kata kunci: Kemahiran komunikasi, keterampilan peribadi, konsep keterampilan, kepentingan keterampilan, teras keterampilan.

\section{Students' Personal Skills as a Form of Communication Skills and Their Importance in the Job Market}

\begin{abstract}
This article discusses students' personal skills as a form of communication skills and their importance in the world of job markets. Communication skills have been identified as an element that helps graduates in improving their personality qualities. Humans communicate because they want to influence the understanding of others, attitudes and even actions of others whether they agree or not on an issue. In addition, communication is also a two-way process in which both parties must respond to a piece of information presented. Therefore, this study was conducted to analyze non-verbal communication skills as well as the level of personal skills of students at UPM and UMS. Data obtained through survey methods were analyzed descriptively and inferentially using descriptive mean analysis, correlation and regression. The findings show that students' awareness of non-verbal communication skills is at a high level. Similarly, the personal skills expressed by them, are also at a high level. While regression analysis found that non-verbal communication skills contributed variance on personal skills by 36.9 per cent. With good skills, students can improve their personal skills. The concept of self-skills
\end{abstract}


covers three main elements, namely communication skills, leadership skills and also group work skills. Graduates who have these three elements will make it easier for them to build a good personality and help them bring themselves into the world of the job market.

Keywords: Communication skills, personal skills, the concept of skills, importance of skills, core skills.

\section{PENGENALAN}

Dalam era yang penuh pancaroba dewasa ini, individu yang ingin memiliki pekerjaan seharusnya bersedia dengan apa jua dugaan dan rintangan. Ini kerana, persaingan di zaman ini terlalu banyak dan organisasi selalunya melihat keterampilan yang dipamerkan oleh setiap individu sewaktu temuduga. Temuduga memainkan peranan yang penting dalam menentukan pengambilan individu untuk bekerja. Dengan memiliki akademik yang cemerlang, sudah pasti menjadikan seseorang individu itu yakin dengan kebolehan yang dimiliki. Namun, prestasi akademik bukan satu-satunya kriteria yang menentukan kejayaan sesuatu temuduga kerja. Keterampilan peribadi juga memainkan peranan penting. Tanpa kemahiran sampingan khususnya kemahiran komunikasi, tidak mungkin melayakkan seseorang itu mendapat pekerjaan kerana majikan lebih meletakkan kemahiran tersebut sebagai syarat utama dalam mendapat tempat di alam pekerjaan.

Tambahan pula, jika dilihat pada zaman sekarang, majikan lebih mengutamakan calon yang memiliki keterampilan peribadi yang menarik. Keterampilan peribadi sebenarnya menjadi tunjang dalam menentukan siapa diri kita sebenarnya. Pembangunan sahsiah amat penting bagi pelajar kerana ia merupakan medium dakwah dan aset penting dalam kehidupan mereka (Shahidan \& Yin, 2017). Bagi memastikan kita menuju abad ke-21 dengan jayanya, Institusi Pengajian Tinggi (IPT) haruslah melahirkan graduan yang berkualiti dan cemerlang. Graduan yang cemerlang adalah mereka yang boleh berkomunikasi, mempunyai keyakinan diri dan juga nilai-nilai murni (Abdul Rahim, 2000). Bagi membentuk graduan yang berkualiti, Chin et al. (2005) menyarankan bahawa kokurikulum harus ditekankan dalam silibus pembelajaran kerana ia dapat membantu pelajar dalam perkembangan minda dan otak yang akan menjadikan pelajar itu boleh menghasilkan kerja yang berkualiti. Kokurikulum adalah penting untuk membina keterampilan peribadi (Nor Suhara \& Jamil, 2010).

Institusi yang dikenali sebagai universiti menjadi tonggak utama dalam menghasilkan sumber tenaga manusia yang bakal merealisasikan hasrat Malaysia untuk menjadi sebuah negara maju pada tahun 2030. Justeru untuk mencapai apa yang diinginkan, maka institusi pendidikan awam dan juga swasta haruslah memainkan peranan yang proaktif dalam membentuk pelajar yang berketerampilan. Empat perkara utama untuk membentuk modal insan yang akan memenuhi keperluan negara yang seimbang ialah jasmani, emosi, rohani dan intelek. Oleh yang demikian, pelbagai usaha perlu dipergiat dan perancangan strategik harus diambil oleh institusi pendidikan bagi melahirkan pelajar yang bukan sahaja mempunyai prestasi akademik yang hebat tepai juga keterampilan diri yang menarik.

Hakikatnya, mempunyai akademik yang baik bukan lagi sandaran atau kunci utama untuk bersaing dalam mendapatkan pekerjaan. Graduan digesa supaya memiliki kemahiran tambahan yang antaranya ialah kemahiran berkomunikasi, mempunyai idea yang bernas dan pengetahuan yang luas, berani menyuarakan pendapat dalam apa jua keadaan (Shaari, 2012). Oleh kerana Malaysia sedang berkembang dengan pesat, maka graduan disarankan untuk mempunyai kemahiran insaniah yang tinggi sejajar dengan kebolehan yang diinginkan oleh majikan. 
Walaupun banyak penambahbaikan telah dilaksanakan bagi mengukuhkan lagi tahap kebolehpasaran graduan IPT, masih terdapat banyak rungutan yang dikemukakan oleh para majikan tentang kualiti para graduan hari ini. Antara rungutan yang sering dikemukakan oleh para majikan adalah kelemahan para graduan dalam aspek kemahiran insaniah seperti kemahiran berkomunikasi, kemahiran membuat keputusan, penguasaan Bahasa Inggeris dan sebagainya (Muhammad, 2012). Di samping itu, Majlis Tindakan Ekonomi Negara (2018) turut menggariskan beberapa faktor yang menjadi penyebab graduan sukar mendapat pekerjaan iaitu kekurangan kemahiran dan pengalaman kerja, ketidaksepadanan antara keperluan industri dengan bidang pengajian graduan, kurang keupayaan untuk berkomunikasi dengan baik terutamanya Bahasa Inggeris, sikap negatif sesetengah graduan terhadap pekerjaan dan kurang kesedaran tentang kewujudan pelbagai peluang pekerjaan.

Dalam kehidupan seharian, kemahiran komunikasi sebenarnya menjadi tonggak kepada keterampilan peribadi seseorang. Manusia akan berkomunikasi untuk saling memahami antara satu sama lain. Kemahiran komunikasi adalah kemampuan untuk berkomunikasi secara berkesan dengan orang lain (Devito, 2013). Kemahiran komunikasi mengandungi pengetahuan tentang komunikasi bukan lisan seperti sentuhan, kedekatan fizikal, pengetahuan tentang cara berinteraksi dengan sewajarnya dan intonasi suara. Peraturan ini mengandungi etika. Etika adalah suatu pertimbangan dalam kemahiran komunikasi interpersonal (Devito, 2013).

Menurut Suranto (2011), komunikasi akan berjalan lancar apabila diselarikan dengan beberapa kemahiran. Antara kemahiran yang harus dikuasai adalah kemahiran bertutur, kemahiran bertanya, kemahiran empati, kemahiran mendengar dan sebagainya. Kemahiran inilah yang diperlukan oleh pelajar untuk mewujudkan komunikasi yang baik kepada orang lain. Pelajar yang memiliki kemahiran ini mampu untuk membentuk keterampilan peribadi mereka kerana dengan kemahiran tersebut, mereka akan menjadi seorang yang berkeyakinan dan berani serta dapat meningkatkan disiplin diri. Hafied Changara (2008) mengatakan bahawa kemahiran komunikasi adalah kemampuan seseorang untuk menyampaikan atau menghantar mesej kepada khalayak. Komunikasi adalah elemen penting dalam menjalani kehidupan seharian. Selain menjadi keperluan, aktiviti komunikasi pada masa yang sama adalah unsur penyusunan masyarakat kerana tidak mungkin manusia tinggal di suatu tempat tanpa berkomunikasi antara satu sama lain.

Namun, bukan semua orang mempunyai kemahiran komunikasi yang baik. Ini dapat dilihat pada sebahagian besar pelajar (Kamaruzzaman, 2016). Kemahiran ini seharusnya dipupuk lebih awal supaya pelajar mampu mewujudkan hubungan sosial yang baik, bagi mencorakkan keterampilan peribadi mereka.

Komunikasi secara umumnya merujuk kepada perkataan dan bukan perkataan yang digunakan ketika proses komunikasi berlaku. Komunikasi bukan lisan pula menurut Knapp dan Hall (2006) merujuk kepada komunikasi yang dilakukan selain daripada perkataan yang membawa makna (seperti contoh pandangan mata, gerak/bahasa tubuh atau intonasi suara). Namun kemudiannya, Seiler, Beall dan Mazer (2016) mendefinisikan komunikasi bukan lisan sebagai semua kelakuan, perbuatan, sifat atau objek (kecuali perkataan) yang menyampaikan pesanan yang mempunyai makna sosial. Ini bermakna komunikasi bukan lisan melibatkan semua bentuk perlakuan, objek, sifat, pesanan atau simbol, sebahagian daripada perkataan atau penggunaan bahasa, sama ada dalam bentuk percakapan atau tulisan. Komunikasi bukan lisan boleh dibahagikan kepada beberapa kategori iaitu komunikasi melibatkan ekspresi muka, tanda, pergerakan tubuh, lirikan mata, sifat fizikal, sentuhan, bauan dan jarak. 
Para sarjana memandang pentingnya komunikasi bukan lisan berbanding komunikasi lisan dalam pengajaran terutama di dalam kelas. Penggunaan komunikasi seharian menunjukkan bahawa seorang pendengar akan memberikan perhatian sebanyak 7 peratus kepada kandungan lisan, 38 peratus kepada perubahan nada suara dan 55 peratus lagi kepada isyarat bahasa badan. Secara keseluruhannya, 93 peratus tumpuan komunikasi adalah kepada mesej komunikasi bukan lisan (Nordin Halias et al., 2017).

\section{KETERAMPILAN PERIBADI DALAM KONTEKS KEMAHIRAN KOMUNIKASI}

Apa itu keterampilan peribadi? Keterampilan adalah suatu kemahiran yang dikurnia dan boleh dipupuk ke atas seseorang individu. Kemampuan manusia untuk mengembangkan kemahiran yang dipunyai memang tidak mudah dan ia perlu dipelajari serta dipraktikkan dengan tekun agar lebih mahir. Kemahiran merupakan ilmu yang secara lahiriahnya ada di dalam diri manusia dan perlu dipelajari secara mendalam supaya mengembangkan kemahiran yang dimiliki. Kemahiran sangat banyak dan ia boleh dipelajari. Kemahiran bukan hanya dijadikan sebagai pengetahuan malah boleh menjadi inspirasi bagi orang yang mahu memikirkannya. Kemahiran juga akan menyebabkan orang lain atau masyarakat sekeliling selesa untuk bersama dengan kita dan tiada perasaan cemburu mahupun dengki atas kejayaan diri kita. Keterampilan yang baik mencerminkan bahawa seseorang itu mempunyai kemahiran emosi yang baik serta berupaya untuk berfikir lebih jauh dan mampu menjadi contoh kepada yang lain. Oleh yang demikian, keterampilan peribadi amat penting untuk dikaji kerana dalam arus globalisasi ini, memiliki pengetahuan yang tinggi belum mampu menjaminkan seseorang itu mendapat kerjaya, namun mereka haruslah mempunyai keterampilan yang baik (Hamidah Norman et al., 2017)

Empat aspek keterampilan menurut Gainer (1998) dalam Yahya Buntat (2004) ialah kemahiran berkomunikasi, kemahiran berhubung, kemahiran komputer dan kemahiran berbudaya. Tambah beliau lagi, keterampilan merupakan salah satu elemen yang ditekankan oleh majikan. Berani membicarakan sesuatu, berani mengambil risiko, mampu berkomunikasi dengan baik adalah antara ciri keterampilan yang harus ada dalam diri graduan (Zain, 2012).

Di Malaysia, majoriti pelajar masih kurang fasih dalam berbahasa Inggeris dan ini telah menimbulkan kebimbangan dalam mendapatkan pekerjaan di masa depan (Miskam \& Saidalvi, 2019). Para penyelidik mendedahkan bahawa orang Malaysia terutamanya pelajar menghadapi masalah pembelajaran yang serius kerana bimbang akan bahasa yang digunakan mereka (Azarfam \& Baki, 2012; Hamzah, 2007; Zhiping \& Paramasivam, 2013). Kajian menunjukkan bahawa pelajar boleh berkomunikasi dengan yakin sekiranya mereka berlatih dalam jumlah yang mencukupi (Lee, 2016; Melchor-Couto, 2017; Villalba \& Luz, 2017). Kemahiran komunikasi lisan dikaitkan secara negatif dan signifikan dengan tahap kegelisahan bahasa asing (Amengual-Pizarro, 2018).

Dengan dunia yang semakin mencabar, graduan tidak mempunyai pilihan sebaliknya perlu melaluinya dengan melatih diri supaya dapat membentuk keterampilan diri yang unggul (Tengku Abdullah, 2011). Bagi membolehkan graduan mendapat tempat di alam pekerjaan, graduan seharusnya mempunyai beberapa garis panduan yang telah disenaraikan oleh majikan. Antara tuntutan majikan ialah boleh berkomunikasi dua hala serta mampu menghasilkan penulisan yang baik, yakin dalam penghujahan, sopan, mampu bekerja dalam kumpulan dan cekap membuat keputusan yang betul dalam masa yang singkat serta berfikir luar daripada kotak (Ahmad, 2009). 
Perkara yang mampu mempengaruhi motivasi diri pelajar ialah keterampilan (Ahmad Esa \& Hisham Jamaludin, 2009) dan segelintir pelajar memandang remeh akan perkara ini walhal ia menjadi tunjang utama dalam pembentukan jati diri. Oleh yang demikian, pelajar yang mempunyai keterampilan diri akan cenderung untuk muncul ke hadapan dan menjadikan diri mereka berani dalam menyuarakan idea dan memberi jawapan tanpa paksaan dan tidak malu dan menjadikan diri mereka contoh kepada yang lain (Zain, 2012). Bukan itu sahaja, malah pelajar juga boleh menambah ilmu yang sedia ada dengan ilmu baharu seperti menggalakkan diri mereka bergaul dengan orang sekeliling yang berbeza agama, budaya dan lebih menarik mereka yang mempunyai pendapat yang berlainan. Dengan itu, mereka akan lebih cenderung untuk memikirkan dan berhujah dalam memantapkan lagi kebolehan diri mereka yang sedia ada.

Keterampilan juga akan membantu pelajar lebih berkeyakinan dalam berhadapan dengan orang. Kajian yang dijalankan oleh Yahya (2004), mendapati bahawa kemahiran utama yang diperlukan dalam diri pelajar ialah kemahiran berkomunikasi dan kemahiran bekerja dalam kumpulan. Dengan adanya kemahiran ini, maka pelajar akan lebih berasa yakin dan mampu menampilkan diri di khalayak ramai. Kokurikulum adalah salah satu cara terbaik untuk membantu pelajar dari segi keterampilan diri. Melalui penglibatan pelajar dalam pelbagai aktiviti, aspek keterampilan dapat diterap dan disemai dalam diri pelajar sama ada disedari atau tidak.

Kajian lain yang menekankan akan keterampilan ialah kajian oleh Ahmad (2009) yang mana kajiannya berkaitan dengan peranan kokurikulum di universiti dalam membentuk keterampilan. Empat aspek keterampilan iaitu kemahiran komunikasi, kepimpinan, kemahiran berkumpulan dan kemahiran keterampilan diketengahkan dalam kajian beliau. Hasil yang diperolehi dapat disimpulkan bahawa aktiviti kokurikulum ini dapat membantu pelajar dalam memantapkan diri mereka sebelum melangkah ke alam pekerjaan.

Dalam artikel Mokhtar Alfakari (2011), beliau menyatakan bahawa majikan kerap memberi maklum balas dan juga komen berkenaan dengan penampilan. Majikan menekankan isu tersebut yang paling utama dalam laporannya. Tidak dapat disangkal lagi bahawa keterampilan menjadi faktor utama pilihan penemuduga dalam mencari calon yang sesuai untuk dijadikan aset dalam organisasi mereka.

Berlainan pula dengan kajian yang dijalankan ke atas 407 orang pelajar di Universiti Teknologi Malaysia (UTM) oleh Arham (2006). Hasil kajian mendapati 238 pelajar memilih untuk bertanya kepada rakan, 146 pelajar memilih bertanya terus kepada pensyarah dan 23 pelajar lebih suka mendiamkan diri. Di samping itu juga, daripada 407 pelajar, 253 pelajar gemar memilih tempat duduk di bahagian tengah dewan kuliah, hanya 99 pelajar yang memilih duduk di bahagian hadapan dan selebihnya 55 orang duduk di bahagian belakang dewan kuliah. Hasil ini menunjukkan pelajar masih kurang berkeyakinan untuk merebut peluang yang ada dan tidak memanfaatkan sepenuhnya waktu di dalam kelas kuliah.

Masih lagi membicarakan berkenaan kurang keyakinan dalam berkomunikasi yang mana dalam kajian yang dijalankan oleh Hafizah (2011) terhadap kualiti pembentangan tugasan dalam kalangan pelajar Diploma Pemasaran di Politeknik Merlimau, terbukti hasil yang diperolehi mendapati pelajar Diploma ini tidak berani dalam menyuarakan pendapat, intonasi suara yang perlahan, tiada pertembungan mata dengan rakan sekelas yang lain, kurang pergerakan badan dan hanya berdiri tegak sahaja. 
Malah majikan sendiri yang datang ke tapak Career Expo UKM 2012 di Universiti Kebangsaan Malaysia (UKM) menyatakan pelajar UKM yang datang ke tapak pameran untuk menghadiri temuduga mempunyai tahap malu yang begitu tinggi, tidak berkeyakinan dan tidak mempunyai kekuatan daya saing serta kurang pengalaman bekerja dalam kumpulan (Anuar 2012). Menurut beliau lagi, majikan merasakan perlunya kemahiran komunikasi yang dapat membezakan mahasiswa yang masih berkomunikasi seperti 'kebudakan' dengan mahasiswa yang berupaya berkomunikasi seperti seorang yang profesional.

\section{ELEMEN KETERAMPILAN PERIBADI}

Elemen keterampilan peribadi terbahagi kepada tiga bahagian utama. Antaranya ialah kemahiran komunikasi, kemahiran kepimpinan dan kemahiran bekerja dalam kumpulan. Kemahiran komunikasi merupakan kemahiran yang paling penting dalam kehidupan seharian seseorang (Mohd Salleh Lebar, 2000). Maklumat yang tidak tepat dan jelas akan menyukarkan pihak penerima mentafsir maklumat dan ini akan disalahertikan. Sebenarnya, mempunyai kesedaran akan kepentingan kemahiran komunikasi banyak membantu pelajar bersikap positif dan menganggap persaingan adalah sesuatu yang hebat. Dengan mempunyai tahap kesedaran yang tinggi, ini akan lebih membuka minda pelajar untuk mencapai pencapaian yang paling tinggi dalam diri mereka dan menjadikan mereka lebih bersemangat untuk berusaha dengan lebih gigih lagi (Abdul Mua'ti, 2003).

Pendapat yang dikemukakan oleh Peter Maguire dan Carolyn Pitceathly (2002) dalam kajian mereka mendapati, dengan adanya pengalaman yang telah dilalui oleh pelajar, maka pelajar akan lebih mengetahui cara berkomunikasi dengan baik. Pelajar akan dapat berinteraksi dengan baik sekiranya mereka mengikuti aktiviti tambahan kokurikulum dalam menambah ilmu yang sedia ada. Ini ternyata selari dengan pendapat yang dikemukakan oleh Ahmad et al. (2005), yang menjelaskan bahawa sekiranya pelajar mengikuti kegiatan kokurikulum, maka pelajar akan lebih mudah membina kemahiran komunikasi dan kemahiran tersebut berpotensi membantu mereka apabila memasuki alam pekerjaan.

Tidak kurang juga kajian yang telah dijalankan oleh Majlis Tindakan Ekonomi Negara (MTEN 2005) yang mendapati daripada 12 kriteria yang disenaraikan oleh para majikan dalam satu tinjauan pengangguran, salah satu daripada tiga kriteria teratas yang disenaraikan oleh pihak majikan ialah kemahiran komunikasi yang baik manakala pencapaian akademik pula berada di tempat yang ke lapan (Marlina et al., 2005). Justeru itu, para graduan perlulah melengkapkan diri dengan kehendak pasaran semasa iaitu mempunyai kemahiran komunikasi yang baik. Selari dengan hasil yang dikatakan oleh Musalmah (2005), komunikasi adalah penghidupan dan seseorang itu perlu memiliki kemahiran komunikasi untuk mencapai kecemerlangan.

Tuntasnya, kemahiran komunikasi merupakan salah satu aspek keterampilan yang paling penting. Tanpa penguasaan kemahiran ini, graduan akan menghadapi kesukaran dalam memperoleh pekerjaan. Ini kerana, majikan lebih melihat aspek komunikasi berbanding akademik. Mempunyai akademik yang baik belum tentu seseorang graduan itu mempunyai tahap penguasaan komunikasi yang tinggi kerana dalam dunia pekerjaan, komunikasi adalah tunjang utama untuk membina keterampilan.

Dari segi kemahiran kepimpinan pula, ia akan terbentuk sekiranya ketua kumpulan mampu memimpin dan mengemudi kumpulan dengan bijak (Gary Yukl, 2001). Dalam erti kata lain, apabila pelajar banyak melibatkan diri mereka dengan aktiviti kerja luar yang lebih memerlukan mereka berhubung dengan ramai orang, mereka akan lebih memiliki sifat 
kepimpinan dan nescaya aktiviti yang dijalankan itu akan berjalan dengan lancar dan mudah dengan adanya sokongan daripada pihak lain. Helen M. Gunter (2001) turut menyokong kenyataan ini dengan mengatakan bahawa pelajar yang banyak melibatkan diri mereka dengan aktiviti kokurikulum akan lebih bijak dalam mengetuai kumpulan.

Pada pendapat pengkaji, pelajar haruslah tahu bagaimana ingin mengawal ahli kumpulan terutamanya ketua kumpulan. Ketua memainkan peranan yang penting dalam mentadbir dan mengurus kumpulan supaya tidak berlaku sebarang salah faham dan ahli kumpulan juga dapat menyiapkan tugasan yang diberi dalam tempoh masa yang telah diberikan.

Justeru, pelajar harus mengambil berat akan kemahiran kepimpinan kerana ia penting dalam pembinaan sifat keterampilan diri yang baik. Seperti contoh, dalam konteks organisasi, ketua organisasi adalah pemimpin di dalam organisasi. Jika ketua gagal dalam mengawal dan memimpin pekerja di dalam organisasi, maka segala kerja yang ingin dijalankan akan tergantung dan tidak mendapat hasil yang lumayan. Pendek kata, pelajar haruslah menguasai kemahiran ini bagi membolehkan mereka memimpin antara satu sama lain dan menjadikan mereka seorang pemimpin yang berkaliber. Melalui penglibatan dalam aktiviti kokurikulum ini, maka pembentukan organisasi dapat dibentuk dan ditingkatkan.

Seterusnya ialah kemahiran bekerja dalam pasukan. Kemahiran ini berkait rapat dengan kemahiran kepimpinan. Sekiranya seorang itu mempunyai ciri kepimpinan yang tinggi, maka ia akan dapat menyelamatkan kumpulannya daripada tersasar dan dapat mengelak sebarang masalah yang akan timbul. Di samping itu, melalui bekerja dalam kumpulan juga, ia dapat mengeratkan lagi silaturahim mereka yang berlainan latar belakang (Syarifah Mariam, 2007).

Pendapat ini turut dipersetujui oleh David (1993) yang menyatakan bahawa kemahiran bekerja dalam kumpulan sangat penting untuk mencapai kejayaan kerana sikap tolong menolong di antara satu sama lain. Kemahiran ini juga dapat membantu semua ahli dalam kumpulan bekerjasama untuk berusaha mencapai kejayaan secara bersama dengan mudah tanpa ada pergaduhan.

Tidak kurang juga hasil yang diperolehi oleh Anizah (2002) dalam kajiannya. Beliau mendapati semangat kerja berpasukan atau kerja berkumpulan akan dapat menjimatkan masa berbanding dengan bekerja sendirian kerana pembahagian tugas akan diberikan kepada ahli kumpulan masing-masing. Bebanan tugas akan menjadi mudah jika diusahakan bersamasama dalam kumpulan.

Dalam erti kata lain, hasil yang akan diperolehi apabila bekerja dalam kumpulan akan lebih baik kerana ahli kumpulan datangnya daripada pelbagai latar belakang dan kemahiran dan ternyata pandangan mereka juga berbeza. Oleh yang demikian, idea yang akan diperolehi juga menarik. Sebagai kesimpulan, sifat membantu antara satu sama lain dalam kumpulan merupakan kemahiran yang patut dikuasai oleh pelajar agar mereka boleh meletakkan diri mereka di dalam satu komuniti dan boleh menjalani kehidupan sosial dengan sempurna. Yang menjadi tarikan apabila bekerja dalam kumpulan ialah pelajar akan terdedah dengan banyak peluang dan saling belajar antara satu sama lain untuk mencapai matlamat secara bersama.

Dunia pekerjaan yang melibatkan kita bekerja dengan orang lain akan membuatkan kita runsing kerana tidak pandai mengawal situasi. Namun, dengan memiliki kemahiran bekerja dalam kumpulan, maka seseorang itu mampu membina keterampilan peribadi mereka dan ini dapat membantu dalam memudahkan lagi urusan kerja. 
Kemahiran komunikasi interpersonal yang membentuk keterampilan peribadi mempunyai ciri berfikir secara meluas dan kompleks, berfikir secara kritis, mengimbangkan kognitif dan emosi, membina hubungan berdasarkan nilai dan ikatan yang lebih kuat, menghormati perbezaan, mengambil risiko dan membuat keputusan berdasarkan akibat masa depan dan mempertimbangkan kesan keputusan untuk orang lain di sekitarnya (Simpson, 2010). Dengan ciri-ciri ini, seseorang itu mempunyai kemampuan untuk membuat keputusan dengan pertimbangan yang matang.

Kemahiran komunikasi interpersonal yang turut melibatkan komunikasi bukan lisan merupakan satu bentuk mesej yang penting kerana boleh mentafsir emosi, personaliti, tujuan dan juga status sosial seseorang. Sekiranya seseorang graduan itu kurang kemahiran komunikasi bukan lisan ini, maka mereka tergolong dalam kategori graduan yang sukar mendapat pekerjaan (Natashadora Muridan, 2013). Ini kerana, salah satu punca terjadinya pengangguran ialah kekurangan kemahiran berkomunikasi.

Menurut Jarvis dan Keeley (2003), graduan seharusnya menjangka pengangguran berkala dan perubahan kerjaya sepanjang hayat mereka. Namun, apa yang menarik ialah graduan bumiputera kembali menarik perhatian apabila terlalu ramai graduan daripada golongan ini menganggur. Graduan yang tidak memiliki nilai tambah dan terlalu memilih pekerjaan adalah sebahagian daripada punca berlakunya pengangguran (Utusan Online, 2018). Kenyataan ini selari dengan kenyataan di dalam akhbar Berita Harian (8 Julai 2019), masih ramai graduan yang menganggur ini dikatakan berpunca daripada kursus pengajian atau silibus yang tidak menepati keperluan semasa industri atau mungkin kualiti siswazah itu sendiri kurang di mata bakal majikan. Walaupun pelbagai inisiatif dan pelaksanaan yang diambil oleh kerajaan dalam hal ini, masih lagi terdapat segelintir mereka yang tidak berjaya. Tidak mempunyai kemahiran dan pengalaman serta tidak dapat memenuhi kehendak majikan menjadi punca kenapa graduan tidak mendapat tempat dalam industri. Bukan itu sahaja, universiti yang menjadi tempat menimba ilmu telah juga berusaha bukan sahaja dari segi akademik, malah universiti turut menyediakan aktiviti yang melibatkan kemahiran komunikasi seperti contoh kemahiran pengucapan awam, kemahiran menulis, kemahiran membaca untuk mencungkil bakat yang sedia ada pada pelajar sebelum mereka melangkah ke alam pekerjaan (Azali Mohamed, 2007).

Wajarnya, pelbagai cara boleh diterapkan untuk penghasilan pelaksanaan keterampilan. Antaranya ialah melalui proses pembelajaran dan pengajaran (P\&P), aktiviti kokurikulum dan penglibatan dalam persatuan. Melalui pengalaman dan keadaan sekeliling juga, keterampilan akan mudah terbentuk. Maka dengan itu, keyakinan akan timbul dan menyebabkan seseorang itu berani berhadapan dengan cabaran. Mereka inilah yang diperlukan oleh negara selaras dengan perubahan struktur ekonomi, sosial dan politik sekarang.

Bagi memantapkan lagi kualiti hasil kerja, majikan telah menggariskan beberapa kriteria dalam pemilihan pekerja yang mereka rasakan boleh menjadi sebahagian ahli kumpulan mereka (Nur Atiqah, 2009) dan juga yang mempunyai keterampilan yang menarik (Lim, 1994). Selari dengan apa yang dikatakan oleh Mason (2009), majikan mahupun organisasi cemerlang memberi keutamaan kepada keperibadian dan keterampilan serta komunikasi yang baik.

Graduan zaman ini malu untuk menyatakan pendapat kerana takut dilabel tidak pandai dan sebagainya. Maka, mereka lebih memilih untuk mendiamkan diri dan tidak bertanya dan sehingga akhirnya memberi masalah kepada diri mereka sendiri. Selain itu, 
pensyarah juga selalunya berdepan dengan masalah di mana pelajar ini kurang menyerlah ketika melakukan pembentangan di dalam kelas yang mempunyai ramai rakan sekelas. Mereka ini akan lebih berkeyakinan sekiranya berjumpa secara personal bersama dengan pensyarah. Oleh yang demikian, demi menjadikan seorang graduan atau mahasiswa itu berjaya dalam alam pekerjaan, maka mereka harus mempersiapkan diri mereka dengan pelbagai kemahiran soft skills yang membuatkan mereka menjadi rebutan para majikan.

Ahmad Esa dan Hisham Jamaludin (2009) menegaskan bahawa sektor awam dan swasta memerlukan pekerja yang mahir yang mempunyai keupayaan berkomunikasi dua hala dan memahami apa yang cuba disampaikan tanpa menyalah tafsir maksud, berfikiran kritis selain boleh bekerja dalam kumpulan. Hakikatnya kini, majikan lebih cenderung untuk melihat kemahiran tambahan selain kelulusan akademik dan ternyata kelulusan akademik itu hanyalah sebagai salah satu syarat dalam pengambilan bekerja. Justeru itu, pelajar yang ingin mengambil hati majikan haruslah mempunyai keperibadian dan berketerampilan yang menarik (Shaari, 2012).

Universiti dan juga graduan sendiri haruslah tidak memandang remeh akan isu keterampilan diri ini kerana dengan memiliki keterampilan yang menarik, ilmu yang luas, serta mempunyai personaliti yang menawan mampu menangkap pandangan majikan dan menjadikan pelajar itu aset di dalam organisasi mereka. Inilah yang menjadi sosok utama IPTA dan IPTS dalam mengukur kebolehpasaran graduan. Oleh yang demikian, Kementerian Pendidikan Malaysia (KPM) telah melaksanakan beberapa program bagi meningkatkan kebolehpasaran graduan. Bagi meningkatkan nilai tambah graduan, pihak kerajaan telah melaksanakan beberapa program yang harus diikuti oleh pelajar demi memperoleh pekerjaan yang relevan dengan keperluan majikan dalam pelbagai sektor.

Oleh kerana permintaan pekerja yang kian bertambah dan juga untuk menjaga kualiti organisasi dan juga kualiti kerja, majikan mementingkan calon pekerja yang mempunyai pelbagai kepakaran serta pemahaman yang merangkumi aspek kemanusiaan dan teknologi (Ariffin, 2010). Majikan mahukan situasi menang-menang, justeru majikan memilih untuk mengambil calon pekerja yang mempunyai disiplin dan mampu melaksanakan tanggungjawab yang diberikan dengan sebaiknya dan setimpal dengan usaha yang telah dilaksanakan oleh mereka.

\section{KEPENTINGAN KETERAMPILAN PERIBADI DALAM KONTEKS KEMAHIRAN KOMUNIKASI}

Pembelajaran di dalam kelas? Adakah ia cukup? Persoalan ini sering bermain di fikiran sesiapa sahaja termasuk ibu bapa dan pelajar sendiri. Mereka yang peka dengan keadaan sekeliling akan mengatakan bahawa pembelajaran di dalam kelas semata-mata adalah tidak mencukupi. Oleh yang demikian, pelajar harus diberi kebebasan untuk meneroka dan berinteraksi dengan persekitaran supaya mereka lebih mengetahui peranan sebagai seorang pelajar dan remaja kepada masyarakat dan negara. Dalam era yang ditempuhi oleh pelajar pada zaman ini, pengkaji beranggapan bahawa, nilai gred itu bukan lagi satu pemangkin kepada pelajar. Yang menjadi tonggak utama ialah kemahiran tambahan seperti kebolehan dalam berkomunikasi, kebolehan bekerja di luar kotak dan sebagainya yang ada pada pelajar itu sendiri. Ternyata Jumali et al. (2011) bersetuju di mana pada pendapat beliau, sistem gred menjadi cabaran kepada pelajar dan menyebabkan tahap penguasaan kemahiran insaniah menurun. 
Halangan ini akan menjadikan graduan sukar mendapatkan pekerjaan. Oleh yang demikian, graduan harus melengkapkan diri mereka dengan aktiviti kokurikulum yang mana mereka perlu lebih banyak bergaul dan lebih banyak mengenali dunia luar. Seperti contoh, pelajar disarankan mengikuti aktiviti yang melibatkan lebih banyak kerja berpasukan, sentiasa aktif dan berfikiran kritis dalam menyelesaikan masalah dan berkebolehan berfikir di luar kotak.

Tambahan pula, dalam mengembangkan bakat dan kemahiran insaniah, kokurikulum menjadi kunci utama dalam pembentukan remaja untuk mencapai sasaran. Penyataan ini disokong oleh Chin et al. (2005) yang mengatakan bahawa kokurikulum dapat memberi banyak manfaat dan kepentingan kepada pelajar apabila mereka mengikuti aktiviti kokurikulum yang melibatkan luar dan dalam kelas.

Keterlibatan remaja di dalam aktiviti kokurikulum membolehkan mereka menggunakan segala kemahiran yang ada bagi menjalankan sesuatu aktiviti. Oleh itu, pendedahan ini akan membolehkan mereka mencungkil potensi diri yang ada tanpa mereka sedari. Lazimnya, mereka yang melibatkan diri dengan aktiviti kokurikulum akan menjadikan mereka seorang yang berkemahiran hasil daripada pengalaman yang diperolehi ketika menjalankan aktiviti kokurikulum tersebut.

Gainer (1998) telah merumuskan bahawa keterampilan individu meliputi kemahiran berkomunikasi, kemahiran berhubung, kemahiran komputer dan kemahiran berbudaya. Tambah beliau lagi, keterampilan merupakan salah satu elemen dalam kemahiran 'employability' iaitu kemahiran dan juga kualiti yang dikehendaki oleh para majikan. Menurut pakar motivasi, terdapat beberapa ciri keterampilan diri iaitu keberanian, aras harga diri yang sihat, menjana minda, berdaya saing serta peningkatan kemahiran berkomunikasi, berbahasa dan juga pengucapan awam (Zain, 2012).

Mohd Salleh Lebar (2000), menjelaskan dalam kehidupan seharian, komunikasi amat penting terutamanya dalam pemindahan maklumat, pengiriman berita dan juga tindak balas orang yang menerima. Sekiranya maklumat yang diterima tidak tepat atau tidak jelas, maka orang yang menerima maklumat mengalami kekeliruan.

Maguire dan Pitceathly (2002) dalam kajian mereka mengatakan bahawa jika seseorang itu ingin memperoleh kemahiran komunikasi, maka mereka harus merasai sendiri pengalaman berinteraksi dengan masyarakat sekeliling dalam menyampaikan sesuatu mesej. Dengan mengikuti aktiviti kokurikulum, maka pelajar lebih mudah untuk berkomunikasi dengan rakan dan juga pensyarah dan ini membolehkan pelajar berkomunikasi dan mendengar maklumat yang disampaikan dengan baik. Pendapat ini disokong oleh Ahmad et al. (2005), yang mengatakan kegiatan kokurikulum berpotensi membantu pelajar apabila mereka bekerja dengan membina kemahiran komunikasi dalam kalangan pelajar yang mengikutinya.

\section{METODOLOGI}

Kajian ini menggunakan kaedah survei. Pengkaji mengambil sampel pelajar di Universiti Putra Malaysia (UPM) dan Universiti Malaysia Sabah (UMS). Kajian ini bertujuan untuk menganalisis keterampilan peribadi pelajar di dua buah universiti awam yang menunjukkan peratus kebolehpasaran yang berbeza. Berdasarkan statistik 2018, kebolehpasaran graduan di UPM ialah 83.5 peratus, manakala UMS ialah 60 peratus. Perbezaan statistik ini telah mendorong pengkaji untuk mengkaji adakah keterampilan peribadi pelajar di kedua-dua universiti ini berbeza sehingga UPM menduduki tempat ketiga dari segi kebolehpasaran graduan bagi 20 
universiti awam di Malaysia, manakala UMS pula menduduki tempat terakhir. Selain memeriksa tahap, kajian ini juga cuba membandingkan sejauh mana dimensi yang terdapat dalam komunikasi bukan lisan mempengaruhi keterampilan peribadi pelajar. Ini adalah penting untuk menentukan sejauh mana dua universiti yang berbeza kadar kebolehpasaran graduannya, juga berbeza dari segi faktor yang menentukan keterampilan peribadi para pelajarnya. Sebanyak 467 set borang soal selidik diedarkan kepada pelajar. Kajian ini menggunakan analisis deskriptif untuk melihat tahap kemahiran komunikasi bukan lisan dan keterampilan peribadi pelajar. Bagi melihat pengaruh kemahiran komunikasi bukan lisan ke atas keterampilan peribadi pelajar pula, kajian ini menggunakan analisis inferensi iaitu regresi.

\section{HASIL KAJIAN DAN PERBINCANGAN}

Berdasarkan analisis deskriptif ke atas 467 maklumat demografi responden, di Universiti Putra Malaysia (UPM) pelajar perempuan iaitu sebanyak 56.7 peratus (115 orang) dan 43.3 peratus lagi adalah lelaki iaitu sebanyak 88 orang. Bagi kategori umur pula, majoriti responden adalah terdiri daripada golongan yang berumur 22-25 tahun iaitu sebanyak 63.5 peratus yang mewakili 129 orang, diikuti dengan responden yang berumur 18-21 tahun sebanyak 35 peratus iaitu 71 orang. Responden yang berumur 26-29 tahun adalah sebanyak 1.5 peratus iaitu hanya tiga orang sahaja. Seterusnya, dari segi profil kaum pula, seramai 82 orang responden adalah Melayu iaitu mewakili 40.4 peratus, diikuti dengan kaum Cina sebanyak 30 peratus iaitu 61 orang. Lain-lain ini terdiri daripada Iban, Bidayuh, Kayan adalah sebanyak 16.7 peratus (34 orang) dan India mewakili 12.8 peratus iaitu seramai 26 orang. Dari segi fakulti pula, 43.8 peratus yang mewakili 89 orang responden datangnya dari Fakulti Ekonomi dan Pengurusan. Kemudian, 42.4 peratus adalah dari Fakulti Kejuruteraan iaitu seramai 86 orang. Seterusnya ialah dari Fakulti Sains iaitu sebanyak 13.8 peratus (28 orang).

Bagi responden di Universiti Malaysia Sabah (UMS) pula, 66.7 peratus (176 orang) daripadanya adalah perempuan dan 33.3 peratus adalah lelaki iaitu sebanyak 88 orang. Manakala kategori umur pula, sebahagian besar responden adalah terdiri daripada golongan yang berumur 22-25 tahun iaitu sebanyak 61.4 peratus yang mewakili 162 orang, diikuti dengan responden yang berumur 18-21 tahun sebanyak 38.3 peratus iaitu 101 orang. Responden yang berumur 26-29 tahun adalah sebanyak 0.4 peratus iaitu hanya seorang sahaja. Seterusnya, dari segi profil kaum pula, seramai 142 orang responden adalah dari kaum lain-lain iaitu mewakili 53.8 peratus iaitu kaum Kadazan, Murut, Dusun, Iban, Bajau, Rungus, Sino, Lunbawang, Bidayuh, Bugis, Tidung, Bisaya, Sungai, Kedayan dan Bolongan, diikuti dengan kaum Melayu sebanyak 33.3 peratus iaitu 88 orang. Kaum Cina pula adalah sebanyak 10.2 peratus ( 27 orang) dan India mewakili 2.7 peratus iaitu seramai 7 orang. Dari segi fakulti pula, 45.5 peratus mewakili 120 orang respoden datangnya dari Fakulti Perniagaan, Ekonomi dan Perakaunan. Kemudian, 37.9 peratus adalah dari Fakulti Sains dan Sumber Alam iaitu seramai 100 orang. Fakulti yang terakhir ialah dari Fakulti Kejuruteraan iaitu sebanyak 16.7 peratus (44 orang).

Analisis deskriptif bagi empat dimensi komunikasi bukan lisan di Universiti Putra Malaysia (UPM) mendapati bahawa purata min yang dicatatkan bagi setiap dimensi ialah intonasi suara ( $\min =5.18)$, ekspresi muka (min=5.58), bahasa badan ( $\min =5.43$ ) dan pergerakan mata ( $\mathrm{min}=5.43$ ) manakala bagi Universiti Malaysia Sabah (UMS) pula, intonasi suara ( $\min =5.18)$, ekspresi muka ( $\min =5.47)$, bahasa badan $(\min =5.31)$ dan pergerakan mata ( $\min =5.36)$. Berdasarkan bacaan min daripada empat dimensi kemahiran komunikasi bukan lisan tersebut menunjukkan, tahap kemahiran komunikasi bukan lisan responden berada 
pada tahap tinggi. Rule of thumb dalam menentukan tahap ialah, tahap tinggi, min=5.01-7.00, sederhana, $\min =3.01-5.00$ dan rendah, $\min =1.00-3.00$.

Bagi keterampilan peribadi pula,hasil kajian mendapati, purata min yang dicatatkan oleh Universiti Putra Malaysia (UPM) bagi setiap dimensi juga berada pada tahap tinggi iaitu, kecerdasan ( $\min =6.11)$, kematangan ( $\min =6.08)$, motivasi $(\min =6.11)$, dan hubungan manusia ( $\min =5.69)$ manakala bagi Universiti Malaysia Sabah (UMS) pula ialah kecerdasan ( $\min =6.07)$, kematangan ( $\min =6.10)$, motivasi ( $\min =6.08)$, dan hubungan manusia (min=5.69). Berdasarkan nilai min yang diperoleh, kedua-dua pemboleh ubah yang diukur iaitu kemahiran komunikasi bukan lisan dan keterampilan peribadi pelajar di UPM dan UMS secara keseluruhannya berada pada tahap tinggi. Ini menunjukkan bahawa mereka bersetuju kemahiran komunikasi bukan lisan dan keterampilan peribadi adalah sangat penting dalam komunikasi keorganisasian bagi mewujudkan organisasi yang dinamik dan mempunyai daya tahan yang kental. Dalam usaha untuk menceburi bidang pekerjaan yang baik, pelajar perlu mempunyai tahap kesedaran yang tinggi terhadap kepentingan kemahiran komunikasi. Pelajar yang mempunyai tahap kesedaran yang tinggi mampu mencapai apa juga yang mereka inginkan dan dengan dorongan yang ada, mereka akan lebih berjaya (Abdul Mua'ti, 2003).

Bagi melihat dengan lebih jauh kemahiran komunikasi bukan lisan dan keterampilan peribadi dalam konteks komunikasi keorganisasian, maka kajian ini cuba melihat kesan atau pengaruh kemahiran komunikasi bukan lisan ke atas keterampilan peribadi. Justeru, ujian regresi dijalankan.

Jadual 1: Ringkasan Model Regresi Kemahiran Komunikasi Bukan Lisan dengan Keterampilan Peribadi

\begin{tabular}{ccccc}
\hline Model & $\mathbf{R}$ & $\begin{array}{c}\text { R Kuasa } \\
\text { Dua }\end{array}$ & $\begin{array}{c}\text { Keselarasan R } \\
\text { Kuasa Dua }\end{array}$ & $\begin{array}{c}\text { Ralat Piawai } \\
\text { Anggaran }\end{array}$ \\
\hline 1 & $.607^{\mathrm{a}}$ & .369 & .363 & .54981
\end{tabular}

a. Peramal (malar): ekspresi muka, bahasa badan, intonasi suara, pergerakan mata

Jadual 1 menunjukkan kombinasi dimensi ekspresi muka, bahasa badan, intonasi suara dan pergerakan mata menyumbang sebanyak 36.9 peratus $\left(R^{2}=.369\right.$; pada nilai $\mathrm{F}=67.419, \mathrm{p}<.01$ ) perubahan ke atas keterampilan peribadi.

Jadual 2: Analisis ANOVA Kemhairan Komunikasi Bukan Lisan dengan Keterampilan Peribadi

\begin{tabular}{|c|c|c|c|c|c|c|}
\hline \multirow[b]{2}{*}{ Model } & & \multicolumn{5}{|c|}{ Min Kuasa } \\
\hline & & Jumlah Kuasa Dua & df & Dua & $\mathbf{F}$ & Sig. \\
\hline \multirow[t]{3}{*}{1} & Regresi & 81.519 & 4 & 20.380 & 67.419 & $.000^{\mathrm{a}}$ \\
\hline & Residual & 139.656 & 462 & .302 & & \\
\hline & Jumlah & 221.175 & 466 & & & \\
\hline
\end{tabular}

a. Peramal (malar): ekspresi muka, bahasa badan, intonasi suara, pergerakan mata

b. Pemboleh ubah bersandar: keterampilan peribadi

Bagaimanapun, Jadual 3 menunjukkan semua empat dimensi menunjukkan bacaan signifikan iaitu ekspresi muka $(t=4.822, p<.05)$, bahasa badan $(t=4.564, p<.05)$, intonasi suara $(\mathrm{t}=4.685, \mathrm{p}<.05)$ dan pergerakan mata $(\mathrm{t}=4.407, \mathrm{p}<.05)$. Ini bermakna semua kemahiran komunikasi bukan lisan memberi pengaruh yang signifikan ke atas keterampilan peribadi. 
Jadual 3: Analisis Ujian t Dimensi Kemahiran Komunikasi Bukan Lisan dengan Keterampilan Peribadi

\begin{tabular}{|c|c|c|c|c|c|c|}
\hline \multicolumn{2}{|c|}{ Model } & \multicolumn{2}{|c|}{ Pekali Tidak Piawai } & \multicolumn{2}{|c|}{ Pekali Piawai } & \multirow[b]{2}{*}{ Sig. } \\
\hline & & B & Ralat Piawai & Beta & $\mathbf{t}$ & \\
\hline \multirow[t]{7}{*}{1} & (Malar) & 2.559 & .214 & & 11.937 & .000 \\
\hline & Ekspresi & & & & & \\
\hline & Muka & .195 & .040 & .224 & 4.822 & .000 \\
\hline & Bahasa & & & & & \\
\hline & Badan & .149 & .033 & .210 & 4.564 & .000 \\
\hline & Intonasi Suara & .161 & .034 & .193 & 4.685 & .000 \\
\hline & Pergerakan Mata & .134 & .030 & .187 & 4.407 & .000 \\
\hline
\end{tabular}

a. Pemboleh ubah bersandar: keterampilan peribadi

Hasil bacaan Beta bagi ekspresi muka ialah .224, bahasa badan ialah .210, seterusnya ialah bagi intonasi suara pula nilai Beta .193 dan yang terakhir pergrakan mata dengan nilai Beta .187. Oleh yang demikian, dapat disimpulkan bahawa ekspresi muka dan bahasa badan memberi sumbangan yang paling besar ke atas keterampilan peribadi.

Komunikasi bukan lisan sama pentingnya dengan komunikasi lisan. Ini kerana keduanya saling bekerjasama dalam proses komunikasi. Dengan adanya komunikasi bukan lisan, ia sebenarnya lebih memberi penekanan, pengulangan, melengkapi dan menggantikan komunikasi lisan sehingga ia lebih mudah ditafsirkan (Nisawatun Ulmi, 2017). Apabila komunikasi lisan dan bukan lisan tidak sekata, maka orang akan percaya kepada komunikasi bukan lisan. Secara keseluruhan, kajian lepas yang ditelusuri mendapati, komunikasi bukan lisan lebih banyak dilihat dari perspektif kepentingan, jenis, bentuk dan tingkah laku komunikasi bukan lisan. Justeru komunikasi bukan setakat apa yang ditutur, tetapi imej yang dipaparkan, gerakan tubuh yang ditunjukkan dan emosi yang dizahirkan, adalah jauh lebih penting untuk memahami mesej yang ingin disampaikan dan mengenali keperibadian seseorang dan juga memudahkan graduan untuk mendapat pekerjaan kerana meraka sudah mahir akan komunikasi tersebut.

Komunikasi bukan lisan yang merangkumi intonasi suara, ekspresi muka, bahasa badan dan pergerakan mata tidak terkecuali berkaitan dengan kecerdasan dan motivasi dalam terkandung dalam keterampilan peribadi. Ini kerana, seseorang pelajar itu harus menyiapkan diri mereka dengan kepantasan akal untuk berfikir agar mereka sentiasa nampak cerdas dan bermotivasi. Ini seraya dapat membantu antara satu sama lain dan dapat meningkatkan lagi kemahiran berkomunikasi pelajar.

Keterampilan atau kecekapan berkomunikasi bukan sekadar dilihat pada cara seseorang itu berkomunikasi, tetapi kecekapan berkomunikasi seseorang bukan sekadar mengetahui tentang kod bahasa tetapi juga harus mengetahui apa-apa yang hendak dikatakan kepada siapa, dan bagaimana hendak mengujarkannya dengan cocok dalam situasisituasi tertentu. Semasa proses komunikasi juga, penutur dan pendengar kadangkadang akan mengalami gangguan komunikasi yang disebabkan oleh kelemahan dan kesukaran untuk menguasai sesuatu bahasa tersebut bagi menyampaikan mesej komunikasinya. Keadaan ini akan mendorong penuturnya menggunakan pelbagai alternatif bagi memastikan mesej yang hendak disampaikannya berjaya. Usaha tersebut dikenali sebagai strategi komunikasi.

Dalam erti kata lain, komunikasi bukan lisan juga melibatkan hubungan mata, pergerakan badan, air muka, pakaian, mendengar dan juga keterampilan. Maka dengan itu dapat disimpulkan bahawa, komunikasi bukan lisan ini sangat berkait rapat dengan 
keterampilan. Ini menunjukkan cara kita menyatakan sesuatu dan bagaimana orang lain mentafsirkan apa yang dibicarakan oleh kita.

\section{KESIMPULAN}

Secara keseluruhannya, kemahiran komunikasi merupakan antara aspek keterampilan yang terpenting. Penguasaan pelajar dalam kemahiran ini sememangnya sangat diperlukan terutamanya apabila pelajar menceburi bidang pekerjaan kelak. Dalam sesebuah temu duga, banyak majikan yang memberikan kedudukan tertinggi kepada kemahiran berkomunikasi sebelum membuat keputusan mengambil graduan tersebut bekerja. Ini kerana majikan tahu bahawa pekerja yang tidak pandai berkomunikasi dengan baik besar kemungkinan tidak dapat menjalankan tugasnya dengan baik, walaupun mempunyai rekod akademik yang cemerlang. Ini kerana komunikasi adalah sebahagian daripada keterampilan peribadi yang akan membentuk personaliti, perwatakan seseorang itu. Dengan adanya komunikasi yang baik dan berkesan, maka seseorang itu akan dapat mempamerkan keperibadian mereka. Didapati bahawa aset yang tidak ternilai pada graduan ialah personalitinya, sikapnya dan juga perwatakannya dari segi kematangan berfikir, membuat analisis dan mencari penyelesaian serta berkebolehan menggunakan kemahiran insaniahnya dalam apa jua keadaan sekalipun. Personaliti yang unggul perlu dimiliki oleh graduan yang ingin menceburi bidang profesioanal seterusnya amat menepati pasaran kerjaya.

Kepentingan komunikasi bukan lisan dalam rantaian komunikasi pastinya tidak dapat disangkal lagi. Komunikasi bukan lisan dapat diibaratkan seperti butiran mutiara yang dapat menyerlahkan lagi proses komunikasi lisan agar rantaian komunikasi itu memberikan kesan kepada 'pemakainya'. Dalam erti kata yang lebih mudah, aspek komunikasi bukan lisan perlu hadir bersama-sama dengan komunikasi lisan untuk melahirkan proses komunikasi yang lebih efektif.

Dalam usaha negara menuju status negara maju menjelang tahun 2030, pelajar perlu dilengkapi dengan pelbagai aspek kemahiran bukan sahaja dengan pencapaian akademik semata-mata malah kemahiran tambahan juga harus dikuasai. Hal ini adalah kerana pelajar adalah merupakan keperluan utama masa depan negara. Yang menjadi tunjang utama dalam mensasarkan golongan graduan untuk memperoleh pekerjaan ialah kemahiran keterampilan diri. Ini akan dapat membantu mereka untuk bersaing dengan pelajar lain secara positif.

Dalam mencapai status negara maju dan menjadikan graduan kita berjaya, graduan haruslah memiliki kriteria yang diinginkan oleh majikan iaitu kebolehan berkomunikasi, kebolehan memimpin organisasi, mengamalkan kerja berkumpulan atau berpasukan dan sentiasa membantu antara satu sama lain. Ini akan menjadikan Malaysia mempunyai graduan yang setanding dengan negara maju seperti Amerika Syarikat dan Jepun. Berdasarkan kepentingan aspek keterampilan dalam diri pelajar, maka wajarlah pelajar mengambil inisiatif untuk memajukan diri dengan menanam kesedaran dalam diri di samping berusaha menguasai pelbagai kemahiran lain melalui aktiviti kokurikulum bagi meluaskan penguasaan pelajar dalam meningkatkan keterampilan diri.

Penutupnya, aspek keterampilan melalui penglibatan pelajar dalam aktiviti kokurikulum merupakan pelengkap kepada pembentukan generasi muda yang kompeten yang mampu mengharumkan nama negara di peringkat antarabangsa dan juga menyahut cabaran era globalisasi. Secara tidak langsung, pembentukan sahsiah diri akan dapat dicapai. Selain daripada memperolehi pengalaman, remaja akan lebih mengenali diri hasil daripada pembelajaran secara tidak langsung. Bukan itu sahaja, malah pelajar akan dapat membantu 
orang lain juga dan ini dapat dipraktikkan ke dalam kehidupan seharian. Penampilan yang baik juga akan menyebabkan orang sekeliling berasa selesa dengan kita dan pergaulan itu akan menjadi mudah di mana sahaja kita berada. Keselesaan itu menjadikan keutamaan dan ia secara langsung dapat membantu diri kita untuk bersikap lebih aktif.

\section{BIODATA}

Noor Afzaliza Nazira Ibrahim ialah pelajar Doktor Falsafah dalam bidang pengkhususan Komunikasi Keorganisasian di Universiti Kebangsaan Malaysia, UKM, Bangi. E-mel: noorafzalizanazira@yahoo.com

Maizatul Haizan Mahbob ialah Pensyarah Kanan di Pusat Kajian Media dan Komunikasi. Bidang pengkhususan beliau ialah Komunikasi Keorganisasian. Minat kajian beliau ialah penerimaan inovasi dan advokasi dasar awam. Antara kajian yang pernah dijalankan ialah penerimaan e-servis kerajaan, penerimaan inovasi sosial dan penerimaan Program Transformasi Kerajaan. E-mel: maiz@ukm.edu.my 


\section{RUJUKAN}

Abdullah, T. (2011). Graduan perlu bina keterampilan diri berdepan globalisasi. BH Online.

Abdul Mua'ti Ahmad. (2003). Komunikasi di tempat kerja. Dewan Bahasa Dan Pustaka.

Abdul Rahim M. Ali. (2000). Ilmu pendidikan DPM. Utusan.

Ahmad, A. (2009). Cabaran utama mahasiwa IPTA. Utusan Malaysia.

Ahmad Esa \& Jamaludin, H. (2009). Peranan kokurikulum di universiti dalam membentuk keterampilan mahasiswa [conference paper]. International Conference on Teaching and Learning in Higher Education 2009 (ICTLHE09).

Amengual-Pizarro, M. (2018). Foreign language classroom anxiety among English for Specific Purposes (ESP) students. International Journal of English Studies, 18(2), 145-159.

Anizah Abdul Razak. (2002). Penglibatan pelajar dalam bidang kokurikulum dan hubungannya dengan pencapaian akademik pelajar: Satu tinjauan ke atas pelajar diploma dan sarjana muda KUITTHO. Penerbit UTHM.

Anizam Mohamed Yusof. (2008). Kemahiran interpersonal di kalangan pelajar diploma kejuruteraan di politeknik [conference paper]. Persidangan Pembangunan Pelajar Peringkat Kebangsaan Universiti Teknologi Malaysia.

Anuar Ahmad. (2012). Pelajar UKM baik tapi belum cukup bagus: Pandangan majikan. Utusan Publishing.

Arham Abdullah, B. M. (2006). Faktor-faktor yang menyumbang kepada kecemerlangan akademik pelajar Universiti Teknologi Malaysia [conference paper]. National Student Development Conference (NASDEC), Kuala Lumpur.

Ariffin, D. M. (2010). Ciri pekerja baru diperlukan majikan. BH Online.

Azarfam, A. Y., \& Baki, R. (2012). Exploring language anxiety regarding speaking skill in Iranian EFL learners in an academic site in Malaysia. International Journal of Applied Linguistics \& English Literature, 1(2), 153-162.

Azizi Yahya, Yusof Boon, \& Amir Hamzah. (2010). Kecerdasan emosi dan hubungannya dengan Pencapaian Akademi dan Tingkalaku Pelajar [seminar paper]. Seminar Antarabangsa CESA, Jun 2005, Universiti Kebangsaan Malaysia.

Berita Harian. (2003). Kursus di IPT tidak berkesan.

Berita Harian. (2004). Misi UTHM lahirkan Mahasiswa Seimbang.

Berita Harian. (2019, July 8). Elak graduan B40 terus kecundang. BH Online. https://www.bharian.com.my/rencana/muka10/

Cangara, H. (2008). Pengantar ilmu komunikasi. PT. Raja Grafindo Persada.

Chin Pek Lian, Low Li Chuen, \& Vivian Low Yen Yeong. (2005). Masalah disiplin pelajar, pendekatan dan penyelesaian. Penerbit UTM.

David, B. G. (1993). Collabarative learning group work and study teams. In, Tools for Teaching. Jossey-Bass.

Devito, J. A. (2013). The interpersonal communication book (13th ed.). Longman.

Gunter, H. M. (2001). Leaders and leadership in education. Paul Chapman Publishing.

Hadijah, S. H. (2011). Mengkaji tahap kompetensi pelajar semasa menjalani latihan industri dari perspektif pihak industri. Melaka: Jabatan Perdagangan.

Hafizah Hussin (2011). Kualiti pembentangan tugasan bagi kursus PM101 principles of marketing: Kajian kes dalam kalangan pelajar diploma pemasaran di Politeknik Merlimau. Jabatan Perdagangan.

Hamidah Norman, Rohailin Zainon, Siti Zuraydah Md Jenil, \& Rusyda Yahya. (2017). Personaliti graduan yang menjadi tarikan organisasi. Jurnal Inovasi Perniagaan, 2(1), 53-61. 
Hamzah, M. H. (2007). Language anxiety among first-year Malay students of the international Islamic college: An investigation of L2 skills, sources of anxiety, and L2 performance [Unpublished masters' thesis]. International Islamic University Malaysia.

Hassan Adnan, \& Raja Roslan Raja Abd Rahman. (2010). Keberkesanan pelaksanaan aktiviti fizikal terhadap pembangunan diri pelajar: Satu tinjauan. Journal of Human Capital Development, 3(2), 23-24.

Hopen, D. (2002). Guiding corporate behaviour: A leadership obligation, not a choice. Journal for Quality and Participation, 25(4), 15-19.

Jabatan Perangkaan Malaysia. (2018, July 16). Siaran akhbar: Statistik utama tenaga buruh di Malaysia. https://www.dosm.gov.my/v1/

Jamaludin Haji Badusah, Rosna Awang Hashim, Mohd Majid Konting, Turiman Suandi, Maria Salih, \& Norhafezah Yusof. (2011). Pembangunan pelajar: Memperkasakan kokurikulum institusi pengajian tinggi. Penerbit Universiti Putra Malaysia.

Jumali Selamat, Khaidzir Ismail, \& Shaharudin Ahmad. (2010). Objektif dan Faedah Berpersatuan. Penerbit UKM.

Kauffan, J. M., Mostert, M. P., Trent, S. C., \& Hallahan, D. P. (1998). Managing classroom behavior: A reflective case-based approach (2nd ed.). Allyn \& Bacon.

Knapp, M. L., \& Hall, J. A. (2006). Nonverbal communication in human interaction (6th ed.). Toronto: Thomson Wadsworth.

Lee, E. J. E. (2016). Reducing international graduate students' language anxiety through oral pronunciation corrections, 56, 78-95.

Maguire, P., \& Pitceathly, C. (2002). Key communication skills and howt to acquire. BMJ Publishing Group.

Maizatul Haizan Mahbob, Nik Anis Syakira, Wan Idros Wan Sulaiman, \& Wan Amizah Wan Mahmud. (2019). Komunikasi strategik dan peranannya untuk mewujudkan komunikasi berkesan dalam organisasi. Jurnal Komunikasi: Malaysian Journal of Communication, 35(2), 49-67.

Marais, P. (2011). The significance of student-teacher involvement in co-curricular activities. International Journal for e-Learning Security, 1(2), 81-88.

Marlina, Sufian Rashid, \& Hassan Ahmad. (2005). Inovasi dalam pedagogi: Kurikulum dan pendidikan Malaysia. IPG KPM.

Marlina Ali, \& Sharom Nordin. (2006). Tahap penguasaan kemahiran berfikiran kritis di kalangan pelajar pendidikan fizik merentas jantina. Buletin Persatuan Pendidikan Sains dan Matematik Johor, 15(1), 99-110.

Mason Geoff, W. G., \& Cranmer, S. (2009). Employbility skills initiatives in higher education: What effects do they have on graduate labours market outcomes. Journal on Education Economics, 17, 1-30.

Melchor-Couto, S. (2017). Foreign language anxiety levels in second life oral interaction. ReCALL, 29(1), 99- 119.

Miskam, N. N., \& Saidalvi, A. (2019). Investigating English language speaking anxiety among Malaysian undergraduate Learners. Asian Social Science, 15(1), 1-7.

Mohd Salleh Lebar. (2000). Pentadbiran pendidikan dan pendidikan di Malaysia. Addison Wesley Longman Malaysia Sdn. Bhd.

Musalmah Yahya. (2005). Penerapan kemahiran komunikasi dalam pembentangan tugasan. Penerbit UTHM. 
Natashadora Muridan. (2013). Penguasaan kemahiran komunikasi interpersonal dalam kalangan pelajar tahun satu Fakulti Pendidikan Teknikal dan Vokasional di UTHM [Laporan Projek Sarjana].

Noor Mohamad Shakil Hameed. (2018, Nov 22). Graduan perlu bukti kemampuan (pp.18). Utusan Malaysia. https://upm.edu.my/akhbar/

Nordin Halias, Zawawi Ismail, \& Harun Baharudin. (2017). Komunikasi bukan lisan dalam pengajaran Bahasa Arab. Penerbit UKM.

Nor Suhara Fadzil, \& Jamil Ahmad. (2010). Kepentingan kokurikulum dalam pendidikan di sekolah menengah. Proceedings of the 4th International Conference on Teacher Education, Join Conference UPI \& UPSI Bandung, Indonesia, 59-69.

Nurol Aleyzan Ghazali, H. O. (2011). Masalah keengganan bertanya soalan dalam kalangan pelajar diploma pemasaran. Melaka: Jabatan Perdagangan.

Nur Atiqah Abdullah, A. K. (2009). Permintaan firma terhadap industri tenaga kerja teknologi maklumat dan komunkasi di Malaysia. Jurnal Teknologi Maklumat \& Multimedia, 7189.

Seiler, W. J., Beall, M. L., \& Mazer, J. P. (2016). Communication: Making connections (9th ed.). Boston: Pearson.

Shaari, N. H. (2012). Model baru ekonomi tinjauan dari perspektif Islam. Kuala Lumpur: Institut Kefahaman Islam Malaysia.

Shahidan Shafie, \& Yin, L. L. (2017). Pembentukan sahsiah berkualiti melalui penghayatan kurikulum pengajian Islam: Satu kajian korelasi di politeknik (conference paper). National Conference on Thinking Culture, Kota Samarahan, Sarawak, Malaysia.

Sharifah Meriam Syed Akil. (2007). Cabaran kepimpinan kokurikulum. Universiti Industri Selangor.

Simpson, A. R. (2010). Young adult development, what the research tells us. Parenting Education \& Research Massachusetts Institute of Technology.

Suranto, A. W. (2011). Komunikasi interpersonal. Yogjakarta: Graha Ilmu.

Villalba, F., \& Luz, A. (2017). The effect of language anxiety in oral production in university students [Master's thesis, ICESI University, Colombia].

Yahya Buntat, \& Muhammad Shahabudin. (2004). Kemahiran komunikasi dalam meningkatkan keyakinan pelajar. Universiti Teknologi Malaysia.

Yukl, G. (2001). Leadership in organizations (6th ed.). Prentice Hall.

Zafir Mohd Makhbul, I. Y. (2012). Kriteria pengambilan dan pemilihan graduan dari perspektif pengurusan sumber manusia. Jurnal Personalia Pelajar, 1, 11-13.

Zhiping, D., \& Paramasivam, S. (2013). Anxiety of speaking english in class among international students in a Malaysian university. International Journal of Education and Research, 1(11), 1-16. 